\title{
Monocytes in inflammatory bowel disease: absolute monocyte counts
}

\author{
AS MEE,* J BERNEY, AND DP JEWELL $†$ \\ From the Academic Departments of Medicine and Haematology, The Royal Free Hospital, London NW3, UK
}

SUMMARY Using a cytochemical staining technique, peripheral blood monocytes have been precisely identified and enumerated in patients with inflammatory bowel disease and compared with healthy and disease control subjects. For ulcerative colitis there was a significant monocytosis, which was closely correlated with the total white cell count and with the activity of the disease. For patients with Crohn's disease, the peripheral blood monocyte count was also raised compared with that of the control groups, but the difference did not reach statistical significance. There was no correlation between the monocyte count in patients with Crohn's disease and the total white cell count or the disease activity. Some of the mechanisms that may influence the production and distribution of peripheral blood monocytes are discussed.

The hallmark of Crohn's disease is the presence of granulomata which occur in $50-70 \%$ of cases. ${ }^{1}$ These granulomata are composed of cells of the macrophage series, ${ }^{2}$ and even in patients in whom granulomata are not found these cells are a prominent feature of the inflammatory infiltrate. In experimental models, tissue macrophages are derived from circulating blood monocytes, ${ }^{3}$ and it is therefore postulated that a similar situation applies in humans. ${ }^{4} \mathrm{~A}$ previous study has shown an increased absolute monocyte count in patients with both Crohn's disease and ulcerative colitis, ${ }^{5}$ although these counts were based on morphological criteria.

Monocyte counts have therefore been re-examined in patients with inflammatory bowel disease using a specific cytochemical staining technique for nonspecific esterase. ${ }^{6}$

\section{Methods}

\section{PATIENTS STUDIED}

Forty-four patients with ulcerative colitis and 40 patients with Crohn's disease were studied, and their monocyte counts were compared with counts obtained from 38 healthy control subjects and from 19 disease control subjects.

The disease control group consisted of patients with either peptic ulceration, chronic pancreatitis,

\footnotetext{
*Present address: The Middlesex Hospital, London W1 †Present address: The John Radcliffe Hospital, Oxford Received for publication 28 January 1980
}

or the irritable bowel syndrome, none of which is thought to be immunologically mediated.

The age and sex distribution of all subjects studied is shown in Table 1 . The diagnoses of ulcerative colitis and Crohn's disease were made on standard clinical, histological, and radiological criteria. For patients with ulcerative colitis, disease severity was graded according to the criteria of Truelove and Witts. ${ }^{7}$ Seven patients had severe disease, 13 moderate disease, 18 mild disease, and six were in remission at the time of the study.

For patients with Crohn's disease, disease severity was graded according to the criteria of de Dombal et al. ${ }^{8}$ Twenty-three patients had moderate or severe disease, and 17 patients were in remission or had only mild disease.

\section{MONOCYTE COUNTS}

For all subjects studied, total white cell counts were carried out on whole venous blood using a Coulter counter. Smears of whole blood were made, and the slides were fixed in buffered formalin for 30 seconds at $4-10^{\circ} \mathrm{C}$. The fixed slides were washed three times

Table 1 Age and sex distribution of subjects studied

\begin{tabular}{lllrl}
\hline Subjects studied & No. & \multicolumn{2}{l}{ Sex } & Mean age (range) \\
\cline { 2 - 4 } & & $M$ & \multicolumn{1}{l}{$F$} & \\
\hline Normal controls & 37 & 25 & 12 & $30 \cdot 4(17-58)$ \\
Disease controls & 19 & 10 & 9 & $46 \cdot 7(22-80)$ \\
Ulcerative colitis & 43 & 27 & 16 & $38 \cdot 8(17-83)$ \\
Crohn's disease & 40 & 14 & 26 & $39 \cdot 8(15-91)$ \\
\hline
\end{tabular}


with distilled water before being air dried for 10-30 minutes. Staining for non-specific esterase was performed by incubating the slides for 1 hour in a stain consisting of $0.3 \mathrm{ml}$ pararosanilin, $0.3 \mathrm{ml} 4 \%$ sodium nitrite, and $0.5 \mathrm{ml} \alpha$-naphthylacetate made up to $10 \mathrm{ml}$ with phosphate buffered saline, $\mathrm{pH} 6 \cdot 1$. After this the slides were washed in distilled water before being counterstained with $1 \%$ methyl green extracted with chloroform.

Absolute monocyte counts and their percentage of the total white cell count were then estimated by counting 1000 consecutive white cells. All slides were coded, and the differential counts were made in ignorance of the diagnosis.

\section{STATISTICAL ANALYSIS}

This was carried out using the analysis of variance for comparison between groups. Simple linear regression was used to determine the coefficient of correlation.

\section{Results}

Table 2 summarises the results of the total white count and the absolute and percentage monocyte counts. The absolute monocyte count (mean \pm SEM) in healthy control subjects was $525 \pm 38$ cells $/ \mu l$. For patients with ulcerative colitis, the monocyte count was $777 \pm 69$ cells $/ \mu 1$, which was significantly higher than that of the control group $(P<0.01)$. For patients with Crohn's disease, the monocyte count was also higher than that of the controls $(634 \pm 49$ cells $/ \mu \mathrm{l})$, but this difference was not significant. Neither the monocyte count in patients with ulcerative colitis nor with Crohn's disease was significantly greater than the count of $591 \pm 63$ cells $/ \mu 1$ found in the disease control group (Fig. 1). Figures 2 and 3 show the relation between the absolute monocyte counts and severity of disease. It will be seen that there is no significant relation between active and inactive Crohn's disease. However, for patients with ulcerative colitis, the monocyte count correlates well with increasing severity of disease.

The majority of patients studied were not on systemic corticosteroids. For those who were, there was no correlation between absolute monocyte counts and steroid dosage. Similarly, there appeared to be no relation between the use of local steroid enemas and absolute monocyte counts. These data are shown in Table 3. There was no correlation with length of history or extent of disease for either Crohn's disease or ulcerative colitis.

Table 3 Absolute monocyte count related to corticosteroids

\begin{tabular}{llrl}
\hline Group & Steroids regime & No. & Abs count + SEM \\
\hline Crohn's disease & No steroids & 21 & $613 \pm 59$ \\
& Oral \pm local & 15 & $679 \pm 104$ \\
& Local only & 4 & $578 \pm 87$ \\
Ulcerative colitis & No steroids & 25 & $809 \pm 91$ \\
& Oral \pm local & 9 & $731 \pm 173$ \\
& Local only & 9 & $766 \pm 176$ \\
\hline
\end{tabular}

For patients with ulcerative colitis there was a significant correlation between the absolute monocyte count and the total white cell count $(r=0.74$; $P<0.001$ ). This was not, however, seen in patients with Crohn's disease, in whom there was no correlation $(r=0.3 ; P>0.05)$.

In terms of percentage counts, patients with Crohn's disease had a lower percentage monocyte count than patients with ulcerative colitis or the healthy control subjects $(P<0.05)$. Patients with active Crohn's disease had lower percentage monocyte counts $(6.5 \pm 0.7 \%)$ than those with inactive disease $(7.4 \pm 0.6 \%)$, but this difference was not significant. Conversely, for patients with ulcerative colitis the percentage monocyte count tended to rise with increasing severity of disease, but the correlation failed to reach statistical significance.

\section{Discussion}

Previous studies on the determination of absolute and percentage monocyte counts in inflammatory bowel disease have been based on morphological criteria using Romanowsky stains. ${ }^{5}$ This depends on a subjective assessment of the nature of the cell type under consideration. Recently, cytochemical techniques have been developed, which allow more objective identification of monocytes. ${ }^{6}$ Thus, staining

Table 2 Total white cell count, absolute monocyte counts, and percentage counts in normal controls, disease controls, and patients with inflammatory bowel disease

\begin{tabular}{lllll}
\hline Group & No. & $\begin{array}{l}\text { White cell count } \\
(\text { mean } \pm S E M)\end{array}$ & $\begin{array}{l}\text { Percentage monocytes } \\
(\text { mean } \pm S E M)\end{array}$ & $\begin{array}{l}\text { Absolute monocyte count } \\
(\text { mean } \pm S E M)\end{array}$ \\
\hline Normal controls & 37 & $6322 \pm 207$ & $8.4 \pm 0.6$ & $525 \pm 38$ \\
Disease controls & 19 & $822 \pm \pm 524$ & $7 \cdot 2 \pm 0.6$ & $59 \pm 62$ \\
Ulcerative colitis & 43 & $9142 \pm 823$ & $8 \cdot 5 \pm 0.6$ & $777 \pm 69$ \\
Crohn's disease & 40 & $9546 \pm 430$ & $6.9 \pm 0.5$ & $634 \pm 49$ \\
\hline
\end{tabular}




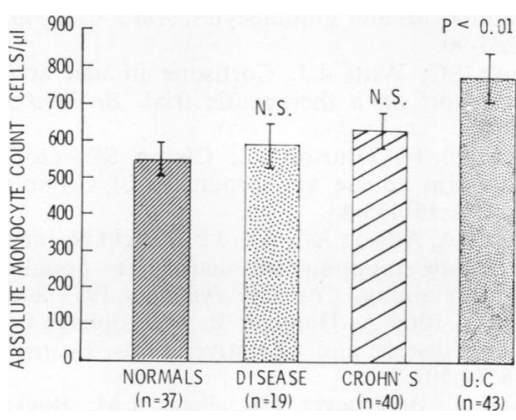

Fig. 1 Absolute monocyte counts in patients with Crohn's disease, ulcerative colitis, and control subjects.

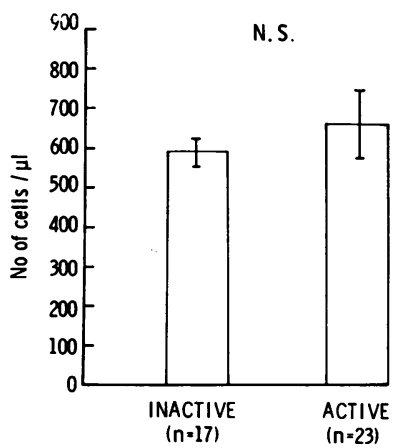

Fig. 2 Absolute monocyte counts in relation to disease severity in patients with Crohn's disease.

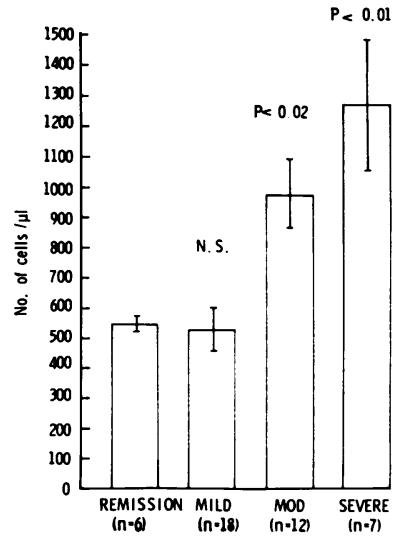

Fig. 3 Absolute monocyte counts in relation to disease severity in patients with ulcerative colitis.

for non-specific esterase enables monocytes to be distinguished from all other elements in peripheral blood and provides a more accurate method of enumerating these cells than the use of morphological criteria. Using non-specific esterase staining, $98 \%$ of phagocytic cells can be identified. ${ }^{9}$
Using cytochemical identification, the present study has shown that, for patients with ulcerative colitis, there is a significant increase in the absolute numbers of peripheral blood monocytes and that the increase correlates with disease activity. For patients with Crohn's disease, the absolute monocyte count tended to be higher than that of the two control groups, but this was not significant, and no relation was found between disease activity and the absolute monocyte count. These results contrast with those of Thayer et al., 5 who found a significantly increased absolute monocyte count in patients with both Crohn's disease and ulcerative colitis, as assessed by Romanowsky staining. The results were not analysed with respect to disease severity, although patients with small bowel Crohn's disease appeared to have a lower absolute monocyte count when compared with those with ileocolitis. This difference was not seen in our series.

A difference emerged between patients with Crohn's disease and ulcerative colitis when absolute monocyte counts were correlated with the total white cell count. For ulcerative colitis, the rise in monocyte counts correlated significantly with the total white cell count. This may reflect a generalised stimulus to the patient's bone marrow. In Crohn's disease, however, there was no relation between the absolute monocyte count and the total white cell count.

Meuret et al.10 have shown that monocyte production by the bone marrow of these patients is increased and that there is no difference between patients with ulcerative colitis and those with Crohn's disease. It seems unlikely, therefore, that impaired production of monocytes explains the lack of correlation between the absolute monocyte and total white cell counts in the Crohn's disease group. Another explanation might be that monocytes are being actively recruited into the inflamed intestine. This is compatible with the large numbers of macrophages seen in Crohn's tissue, which are probably derived from circulating blood monocytes, and also with the lower numbers of circulating monocytes seen in Crohn's disease compared with ulcerative colitis. Finally, the discrepancy between the total white count and the absolute monocyte count in patients with ulcerative colitis and Crohn's disease may reflect different stimuli to monocyte production. It is known that macrophages produce colony stimulating factor which stimulates stem cells to differentiate into monocytes and granulocytes. ${ }^{11}$ In mice, a similar factor has been shown to be liberated from macrophages which is specific for monocytopoiesis. ${ }^{12}$ Furthermore, macrophages also synthesise prostaglandin $\mathrm{E}$ and, when the cells are present in sufficient numbers, the prostaglandin 
acts as a negative feedback mechanism and inhibits the action of colony stimulating factor. ${ }^{11}$ It has been shown that there are increased concentrations of both prostaglandin and prostaglandin synthetase in the inflamed mucosa of patients with ulcerative colitis. ${ }^{13}$ Although similar data are not available in Crohn's disease, it seems likely that the peripheral blood monocyte count may represent the end result of an interplay of these various factors.

ASM was supported by the Stanley Johnson Trust.

\section{References}

${ }^{1}$ Morson BC. Histopathology. In: Engel A, Larssen T (eds). Regional Enteritis: Fifth Skandia International Symposia. Nordiska Bokhandelns Forlag, Stockholm, 1971;15-33.

Turk JL. Granuloma formation in lymph nodes. Proc $R$ Soc Med 1971;64:942-4.

${ }^{3}$ Spector WG, Walters MN-I, Willoughby DA. The origin of the mononuclear cells in inflammatory exudates induced by fibrinogen. J Path Bact 1965;90:181-92.

4 Thayer WR. The immunopathology of intestinal granulomatous disease. In:Frontiers of Gastrointestinal Research. Basel: Karger, 1975;74-124.

5 Thayer WR, Charland C, Field CE. The subpopulations of circulating white blood cells in inflammatory bowel disease. Gastroenterology 1976;71:379-84.

- Yam LT, Li CY, Crosby WH. Cytochemical identification of monocytes and granulocytes. Am J Clin Pathol 1971; 55:283-90.

'Truelove SC, Witts LJ. Cortisone in ulcerative colitis: final report on a therapeutic trial. $B r M e d J$ 1955;2: 1041-8.

8 de Dombal FT, Burton IL, Clamp SE, Goligher JC. Short term course and prognosis of Crohn's disease. Gut 1974;15:435-43.

- Horwitz DA, Allison AC, Ward P, Knight N. Identification of human mononuclear leukocyte populations by esterase staining. Clin Exp Immunol 1977;30:289-98.

10 Meuret G, Bitzi A, Hammer B. Macrophage turnover in Crohn's disease and ulcerative colitis. Gastroenterology $1978 ; 74: 501-3$.

${ }^{11}$ Kurland J, Broxmeyer HE, Pelus LM, Bockman RS, Moore MAS. Role for monocyte-macrophage derived colony stimulating factor and prostaglandin $E$ in the positive and negative feedback control of myeloid stem cell proliferation. Blood 1978;52:388-407.

12 van Furth R, van Waarde D, Thompson J, Gassman AE. The regulation of the participation of mononuclear phagocytes in inflammatory responses. In: Bayer symposium VI: Experimental Models of Chronic Inflammatory Diseases. Berlin, Heidelberg: Springer Verlag, 1977;302-26.

${ }^{13}$ Sharon P, Ligumsky M, Rachmilewitz D, Zor U. Role of prostaglandins in ulcerative colitis. Enhanced production during active disease and inhibition by sulfasalazine. Gastroenterology 1978;75:638-40.

Requests for reprints to: Dr DP Jewell, The John Radcliffe Hospital, Headington, Oxford, UK. 